Check for updates

Cite this: RSC Adv., 2019, 9, 28953

Received 9th April 2019

Accepted 1st July 2019

DOI: $10.1039 / \mathrm{c} 9 \mathrm{ra02663k}$

rsc.li/rsc-advances

\section{A graphite-modified natural stibnite mineral as a high-performance anode material for sodium-ion storage}

\author{
Hongliang Li, (D) ${ }^{a}$ Mingxiang Deng, ${ }^{* b}$ Hongshuai Hou (D) *a and Xiaobo Ji (D) a
}

Recently, $\mathrm{Sb}_{2} \mathrm{~S}_{3}$ has drawn extensive interest in the energy storage domain due to its high theoretical capacity of $946 \mathrm{~mA} \mathrm{~h} \mathrm{~g}^{-1}$. However, the inherent disadvantages of serious volume expansion and poor conductivity restrict the development of $\mathrm{Sb}_{2} \mathrm{~S}_{3}$ for its application in SIBs. In addition, chemical synthesis is a main method to prepare $\mathrm{Sb}_{2} \mathrm{~S}_{3}$, which is commonly accompanied by environmental pollution and excessive energy consumption. Herein, the natural stibnite mineral was directly applied in SIBs after modification with graphite via an effective and facile approach. The novel composites exhibited excellent electrochemical properties with higher reversible capacity, better rate capability and more outstanding cycling stability than the bare natural stibnite mineral. Briefly, this study is anticipated to provide a reference for the development of natural minerals as first-hand materials in energy storage and a new approach to improve natural stibnite mineral composites for their application as anodes in SIBs.

\section{Introduction}

With the rapid growth of large-scale energy storage and electric vehicle market, the demand for rechargeable lithium-ion batteries (LIBs) is also continuously increasing. However, some barriers, including the limited and uneven distribution of lithium resources in the world, strictly hamper the further development of LIBs; ${ }^{1}$ in this regard, sodium-ion batteries (SIB) can be an effective supplementary artifice for LIBs in the largescale energy storage domain owing to abundant sodium resources with even global distribution and similar electrochemical energy storage principles of SIBs to LIBs. ${ }^{2,3}$ However, the larger radius of sodium ions $(0.102 \mathrm{~nm})$ and the higher energy cost for the formation of graphite intercalation compounds as compared to the case of commercial graphite anode materials in LIBs hinder the application of SIBs. Some amorphous carbon materials, such as porous carbons, carbon tubes, carbon nanosheets, and doped carbons, have been confirmed to possess good sodium storage performances. ${ }^{4-8}$ Since the standard electrode potential of $\mathrm{Na} / \mathrm{Na}^{+}(-2.71 \mathrm{~V} v s$. SHE) is higher than that of $\mathrm{Li}^{\prime} \mathrm{Li}^{+}(-3.04 \mathrm{~V} v$ s. SHE $)$ and the specific capacities of most carbon anode materials are less than $400 \mathrm{~mA} \mathrm{~h} \mathrm{~g}{ }^{-1}$, these factors would limit the energy density of SIBs. Hence, it is significant to develop and design new materials with high capacity and long cycle life for SIBs.

${ }^{a}$ College of Chemistry and Chemical Engineering, Central South University, Changsha, 410083, China. E-mail: hs-hou@csu.edu.cn; Fax: +86-731-88879616; Tel: +86-73188877237

${ }^{b}$ College of Science, Central South University of Forestry and Technology, Changsha, 410004, China.E-mail:511584588@qq.com
$\mathrm{Sb}_{2} \mathrm{~S}_{3}$ has gained widespread attention as an anode material for SIBs because of its high theoretical capacity of $946 \mathrm{~mA} \mathrm{~h} \mathrm{~g}^{-1}$ based on both the conversion reaction: $\mathrm{Sb}_{2} \mathrm{~S}_{3}+6 \mathrm{Na}^{+}+6 \mathrm{e}^{-} \rightarrow$ $2 \mathrm{Sb}+3 \mathrm{Na}_{2} \mathrm{~S}$, and the alloying reaction: $2 \mathrm{Sb}+6 \mathrm{Na}^{+}+6 \mathrm{e}^{-} \rightarrow$ $2 \mathrm{Na}_{3} \mathrm{Sb}$, corresponding to twelve moles of sodium ions and electrons stored in one mole of $\mathrm{Sb}_{2} \mathrm{~S}_{3} \cdot{ }^{9,10}$ However, similar to the case of other sulfides, the serious volume change during the electrochemical reaction process would lead to poor reversibility and cycling performance. Moreover, because of a huge band gap energy (1.72 eV), $\mathrm{Sb}_{2} \mathrm{~S}_{3}$ exhibits poor conductivity at room temperature $\left(10^{-8}\right.$ to $\left.10^{-9} \mathrm{~S} \mathrm{~cm}^{-1}\right){ }^{11}$ To address these issues, some methods have been applied that can be summarized as follows: (1) the design of a unique morphology or porous materials, such as bundle-like $\mathrm{Sb}_{2} \mathrm{~S}_{3}$ (ref. 12) and flowerlike $\mathrm{Sb}_{2} \mathrm{~S}_{3},{ }^{13}$ to alleviate the volume changes and (2) combining $\mathrm{Sb}_{2} \mathrm{~S}_{3}$ with carbon materials or other conductive materials (graphite, ${ }^{9}$ graphene, ${ }^{14}$ polypyrrole,${ }^{10}$ and carbon fiber ${ }^{15}$ ).

As is known, the $\mathrm{Sb}_{2} \mathrm{~S}_{3}$ compound is generally prepared by chemical synthesis methods such as hydrothermal reaction, ${ }^{16}$ solvothermal reaction, ${ }^{17}$ and vacuum thermal evaporation. ${ }^{18}$ The abovementioned methods have several or fewer problems: complicated procedures, more by-products, low yield and others. Furthermore, the $\mathrm{Sb}$ element in reaction agents $\left(\mathrm{SbCl}_{3}\right.$, $\mathrm{Sb}\left(\mathrm{NO}_{3}\right)_{3}$, and $\left.\mathrm{SbF}_{3}\right)$ that are the main components in the preparation of $\mathrm{Sb}_{2} \mathrm{~S}_{3}$ is obtained from stibnite or other antimony minerals via different extraction techniques; the traditional and common extraction approaches of the mineral include electrolysis in an alkaline or strong acid solution, multiple volatilization, smelting and roasting reduction method, which cause high pollution, high time and energy consumption, and the generation of more hazardous waste. 
Therefore, stibnite or other antimony minerals are directly utilized as active materials in electrodes, which can effectively avoid the middle steps of $\mathrm{Sb}$ extraction as well as the synthesis of $\mathrm{Sb}_{2} \mathrm{~S}_{3}$ that meet the environmentally friendly concept. Stibnite is a primary $\mathrm{Sb}_{2} \mathrm{~S}_{3}$ mineral and belongs to the orthorhombic system $\left(a_{0}=11.20 \AA, b_{0}=11.28 \AA\right.$, and $\left.c_{0}=3.83 \AA\right)$, which has been found in huge crystals and crystal clusters in many regions. ${ }^{19}$ Note that the natural pure mineral usually exhibits unfavorable electrochemical properties. ${ }^{20}$ Hence, it is necessary to improve the electrochemical sodium storage performances of the natural mineral with green manufacture methods.

In this study, the natural stibnite minerals that act as the main active materials have been directly applied for sodium storage. To improve the electrochemical performance of the natural stibnite ore, an effective and unsophisticated approach was adopted to prepare graphite/stibnite $\left(\mathrm{G} / \mathrm{Sb}_{2} \mathrm{~S}_{3}\right)$ anode materials with excellent properties via the anchoring of the natural stibnite mineral on graphite under facile conditions. Furthermore, the $\mathrm{G} / \mathrm{Sb}_{2} \mathrm{~S}_{3}$ composites exhibit better electrochemical behaviors than the pure natural stibnite mineral owing to the introduction of graphite, which has a lamellar structure and high electric conductivity; this indicates the potentials of this mineral for large-scale energy storage applications; finally, this study is expected to promote the development of antimony sulfide materials that are eco-friendly and consume less energy and also offers a reference that natural minerals can be fully used as first-hand materials in energy storage.

\section{Experimental}

\subsection{Preparation of active graphite and $\mathrm{G} / \mathrm{Sb}_{2} \mathrm{~S}_{3}$}

All reagents were purchased and used without further purification. The procedures for the formation of active graphite were conducted as follows: (1) the commercial graphite was dispersed in mixed acid $\left(\mathrm{HNO}_{3}: \mathrm{H}_{2} \mathrm{SO}_{4}=3: 1\right.$, v/v) under magnetic stirring and then refluxed under $80{ }^{\circ} \mathrm{C}$; (2) after $2 \mathrm{~h}$, the active graphite was washed to become neutral and obtained. The $\mathrm{G} / \mathrm{Sb}_{2} \mathrm{~S}_{3}$ composites were prepared as follows: (1) $0.1 \mathrm{~g}$ active graphite was dispersed in $20 \mathrm{ml}$ deionized water under ultrasonication for $4 \mathrm{~h}$ as the A solution; (2) $0.2 \mathrm{~g}$ natural stibnite ore $\left(\mathrm{Sb}_{2} \mathrm{~S}_{3} \geq 99 \%\right)$ was dispersed in $30 \mathrm{ml}$ ethylene glycol under ultrasonication for $4 \mathrm{~h}$ as the B solution; (3) the A solution was added to the $\mathrm{B}$ solution, and then, the mixed solution was further stirred for $24 \mathrm{~h}$; and (4) the mixed solution was transferred to a hydrothermal reactor at $150{ }^{\circ} \mathrm{C}$ for $12 \mathrm{~h}$, and finally, the $\mathrm{G} / \mathrm{Sb}_{2} \mathrm{~S}_{3}$ composites were washed and obtained.

\subsection{Material characterization}

Thermogravimetric analysis (TGA, NETZSCH STA449F3), X-ray photoelectron spectroscopy (XPS a K-alpha 1063), X-ray diffraction (XRD, Bruker D8 diffractometer, $\mathrm{Cu} \mathrm{K} \alpha$ radiation), transmission electron microscopy (TEM, JEM-2100F), scanning electron microscopy (SEM, FEI Quanta 200) and Raman spectroscopy (Renishaw inVia, UK, the wavelength of 0.1542 $\mathrm{nm}$ ) were used to analyse the composites.

\subsection{Electrochemical measurements}

The electrode slurry was made up of $70 \mathrm{wt} \% \mathrm{G} / \mathrm{Sb}_{2} \mathrm{~S}_{3}$ composites, $15 \mathrm{wt} \%$ carboxymethyl cellulose (CMC) and $15 \mathrm{wt} \%$ super $\mathrm{P}$, which were dissolved in deionized water. Then, the even slurry was cast on a $\mathrm{Cu}$ foil followed by drying at $80{ }^{\circ} \mathrm{C}$ for $8 \mathrm{~h}$. The electrolyte consists of $1 \mathrm{M} \mathrm{NaClO}_{4}$ dissolved in propylene carbonate (PC) with additional 5\% fluoroethylene carbonate (FEC). The electrochemical properties were characterized by the CR2016-type half-cells with Celgard 2400 as the polypropylene separator, which were assembled in a glove box under an $\mathrm{Ar}$ atmosphere. Cyclic voltammetry $(\mathrm{CV})$ was conducted at the scan rate of $0.1 \mathrm{mV} \mathrm{s}^{-1}$ in the voltage range from 0.01 to $2.5 \mathrm{~V}$. Galvanostatic cycling and rate performances were tested at different current densities via an Arbin battery cycler (BT2000) in the voltage range from 0.01 to $2.5 \mathrm{~V}$. Electrochemical impedance spectroscopy (EIS) was conducted in the frequency range from $0.01 \mathrm{~Hz}$ to $100 \mathrm{kHz}$ using the CHI660E electrochemical workstation.

\section{Results and discussion}

To analyse the crystal structure, the $\mathrm{G} / \mathrm{Sb}_{2} \mathrm{~S}_{3}$ composites and stibnite mineral were investigated via X-ray diffraction (XRD). As illustrated in Fig. 1a, all the observed diffraction peaks were well matched to the orthorhombic phase of antimony sulfide (PDF\# 42-1393, Pnma (62), $a=10.9590 \AA, b=2.8060 \AA$, and $c=10.9830$ $\AA)$. These peaks were located at around $15.7^{\circ}, 17.5^{\circ}, 22.3^{\circ}, 24.9^{\circ}$, $29.3^{\circ}, 32.3^{\circ}, 35.5^{\circ}$ and $54.6^{\circ}$, which belonged to the (200), (120), (220), (130), (211), (221), (240) and (630) crystal planes of $\mathrm{Sb}_{2} \mathrm{~S}_{3}$, respectively. Note that a sharp and intense peak of graphite at around $26.3^{\circ}$ can be observed, which corresponds to the (002) crystal planes of graphite. ${ }^{21}$ Evidently, no other peaks were observed; this indicated high purity of the composites. Moreover, the peaks of the $\mathrm{G} / \mathrm{Sb}_{2} \mathrm{~S}_{3}$ composites are sharp and pointed, indicating that these composites have a good crystalline nature. ${ }^{22}$ As presented in Fig. 1b, thermogravimetric analysis (TGA) was conducted to compute the $\mathrm{Sb}_{2} \mathrm{~S}_{3}$ content in the G/ $\mathrm{Sb}_{2} \mathrm{~S}_{3}$ composite under an air atmosphere from room temperature to $800{ }^{\circ} \mathrm{C}$. With an increase in temperature, the carbon matrix was burned into $\mathrm{CO}_{2}$, and $\mathrm{Sb}_{2} \mathrm{~S}_{3}$ was converted into $\mathrm{Sb}_{2} \mathrm{O}_{4} \cdot{ }^{23}$ Finally, the content of $\mathrm{Sb}_{2} \mathrm{~S}_{3}$ in the $\mathrm{G} / \mathrm{Sb}_{2} \mathrm{~S}_{3}$ composite was determined to be $66.68 \mathrm{wt} \%$.

Raman spectroscopy was conducted to investigate the variation of $\mathrm{G} / \mathrm{Sb}_{2} \mathrm{~S}_{3}$ composite and stibnite. As shown in Fig. 1c, the typical peaks of $\mathrm{Sb}_{2} \mathrm{~S}_{3}$ were located at the range from 100 to $600 \mathrm{~cm}^{-1}$, and two obvious and intense peaks corresponding to the D-band and G-band of the graphite were observed. The peak at $1354 \mathrm{~cm}^{-1}$ was ascribed to the D-band, and a particular peak of the $\mathrm{C}_{\mathrm{sp}^{3}}$ hybrid orbital resulted from the disordered arrangement of carbon atoms or lattice defects $;^{24}$ the other peak at $1581 \mathrm{~cm}^{-1}$ was attributed to the G-band, indicating an ordered lattice structure originating from the vibration of $\mathrm{C}_{\mathrm{sp}^{2}}$ in the plane. ${ }^{25}$ Generally, the disordered extent of the carbon 

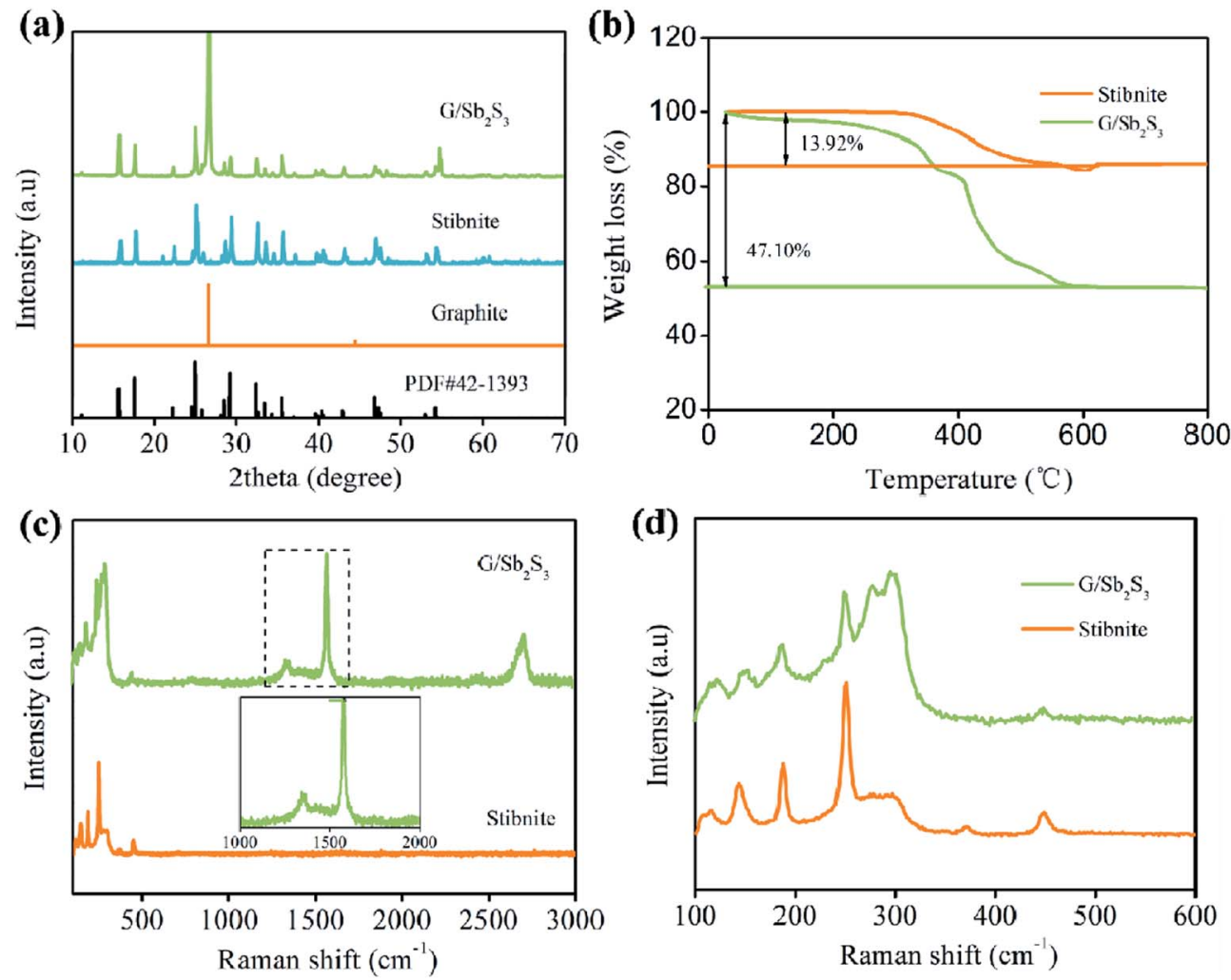

Fig. 1 (a) XRD patterns of $G / S_{2} S_{3}$ and stibnite. (b) TGA curves of $G / S b_{2} S_{3}$ and stibnite. (c) Raman spectra of $G / S b_{2} S_{3}$ and stibnite. (d) Raman spectra of $\mathrm{Sb}-\mathrm{S}$.
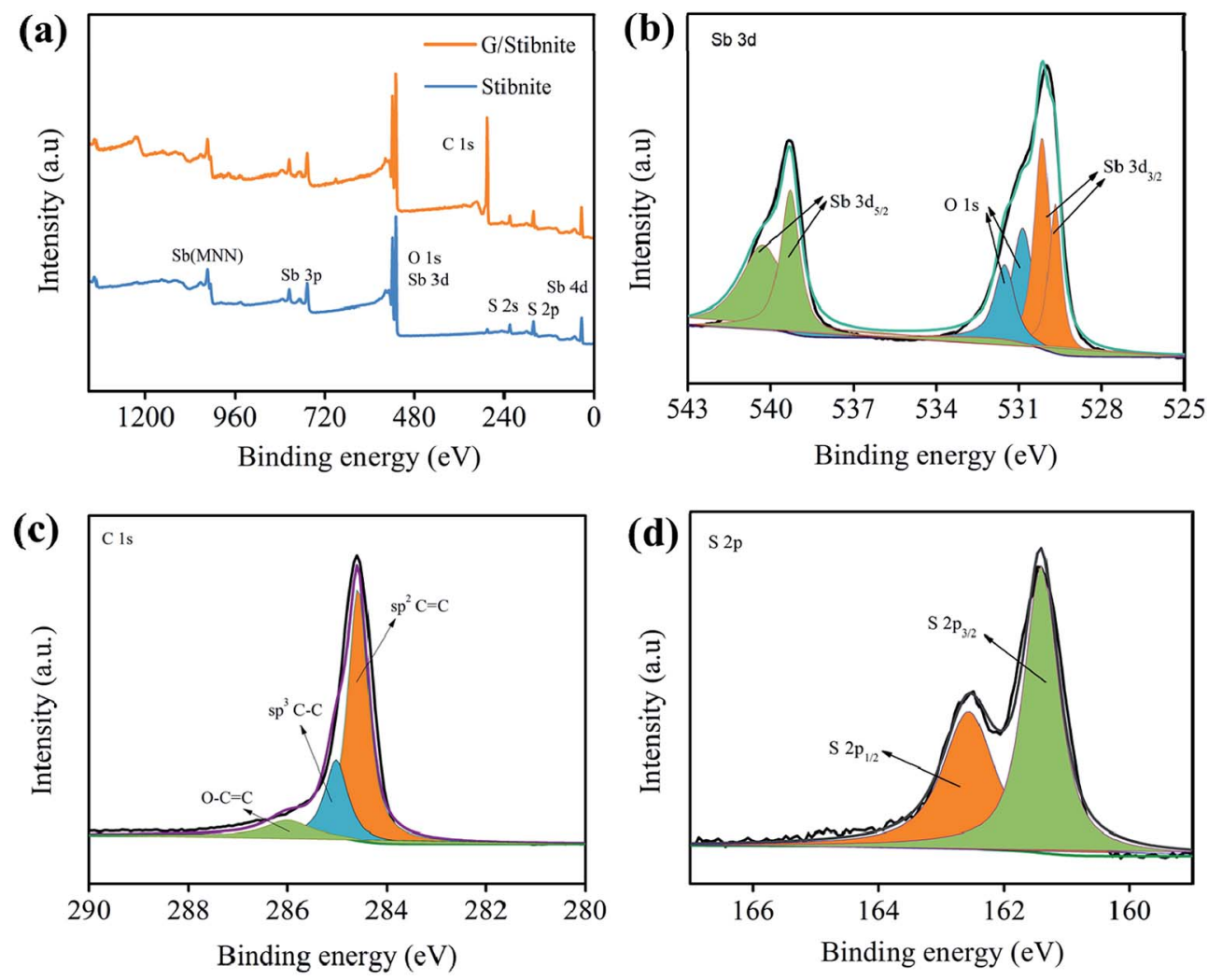

Fig. 2 (a) XPS survey of $\mathrm{G} / \mathrm{Sb}_{2} \mathrm{~S}_{3}$ and stibnite. The corresponding high-resolution spectra of $\mathrm{Sb}$ (b), $\mathrm{S}$ (c) and $\mathrm{C}$ (d). 
materials could be expressed via the integrated intensity ratio $I_{\mathrm{D}} / I_{\mathrm{G}}$, which was 0.15 in the $\mathrm{G} / \mathrm{Sb}_{2} \mathrm{~S}_{3}$ composite, suggesting that the graphite still maintained a highly complete structure after the activation procedure. As depicted in Fig. 1d, the typical peaks of $\mathrm{Sb}_{2} \mathrm{~S}_{3}$ are located at 122, 149, 187, 246, 309 and $446 \mathrm{~cm}^{-1}$, indicating the $\mathrm{S}-\mathrm{Sb}$ stretching vibration and $\mathrm{S}-\mathrm{Sb}-\mathrm{S}$ bending vibration. ${ }^{26}$ Practically, the peaks at 122, 149 and $187 \mathrm{~cm}^{-1}$ are associated with the S-Sb-S bending vibration, and the shift at $246 \mathrm{~cm}^{-1}$ is related to the $\mathrm{S}-\mathrm{Sb}$ stretching, indicating well-crystallinity of the proposed materials. The peak at $309 \mathrm{~cm}^{-1}$ was assigned to the symmetric vibration of the $C_{3 \mathrm{v}}$ symmetric pyramidal $\mathrm{SbS}_{3}$ unit. ${ }^{27}$ Specially, the inconspicuous peak at $446 \mathrm{~cm}^{-1}$ was attributed to the symmetric stretching of $\mathrm{Sb}-\mathrm{S}-\mathrm{S}-\mathrm{Sb}$.

To characterize the chemical composition and surface electronic states of $\mathrm{G} / \mathrm{Sb}_{2} \mathrm{~S}_{3}$, X-ray photoelectron spectroscopy (XPS) was conducted. As exhibited in Fig. 2a, these peaks of $\mathrm{Sb}_{2} \mathrm{~S}_{3}$ were especially obvious from $\mathrm{Sb}$ (4d, 3d, 3p, 3s, Sb MNN) and $\mathrm{S}$ $(2 \mathrm{p}, 2 \mathrm{~s})$, and all other peaks were weak and broad, which could be due to energy loss. ${ }^{28}$ In addition, it is obvious that many researchers have studied the $\mathrm{Sb} 3 \mathrm{~d}$ spectroscopy of antimony compounds because of the higher intensity of $\mathrm{Sb} 3 \mathrm{~d}$ than that of $\mathrm{Sb} 4 \mathrm{~d}$. As illustrated in Fig. $2 \mathrm{~b}$, the peaks of $\mathrm{Sb} 3 \mathrm{~d}_{3 / 2}$ are located at 539.2 and $540.1 \mathrm{eV}$, whereas those of $\mathrm{Sb} 3 \mathrm{~d}_{5 / 2}$ are located at 529.6 and $530.1 \mathrm{eV}$, indicating the existence of $\mathrm{Sb}^{3+} \cdot{ }^{29}$ As shown in Fig. 2c, the peaks at 284.6, 285 and $286.1 \mathrm{eV}$ are related to $\mathrm{C}=$ $\mathrm{C}, \mathrm{C}-\mathrm{C}$ and $\mathrm{O}-\mathrm{C}=\mathrm{C}$, respectively, suggesting the existence of oxygen-containing functional groups that may suffer from partial oxidation during the activation step of graphite. ${ }^{\mathbf{3 0 , 3 1}}$ The S 2p spectrum in Fig. 2d exhibits peaks at 161.3 and $162.5 \mathrm{eV}$, assigned to $S 2 p_{3 / 2}$ and $S 2 p_{1 / 2}$, respectively, which are confirmed to be a single doublet from the S-Sb bonds. ${ }^{32}$

The detailed morphology and crystal structure of the $\mathrm{G} / \mathrm{Sb}_{2} \mathrm{~S}_{3}$ composites and stibnite mineral were observed using a scanning electron microscope (SEM) and transmission electron microscope (TEM). As observed in Fig. 3a and b, the stibnite mineral has indistinctive morphology and uneven particle size. As observed from Fig. 3c-f, the small stibnite ore particles are uniformly decorated on the bulk graphite with the average dimension of around $10 \mu \mathrm{m}$, which can effectively enhance the conductivity of composites. As shown in the Fig. $3 \mathrm{~g}$ and $\mathrm{h}$, the lattice distances of $0.36 \mathrm{~nm}$ and $0.51 \mathrm{~nm}$ are assigned to the (130) plane and (120) plane of orthorhombic $\mathrm{Sb}_{2} \mathrm{~S}_{3}$ crystals, respectively, which are consistent with the analysis of XRD. ${ }^{33,34}$ Moreover, the lattice rim of $0.34 \mathrm{~nm}$ corresponds to the (002) plane of graphite. ${ }^{35}$
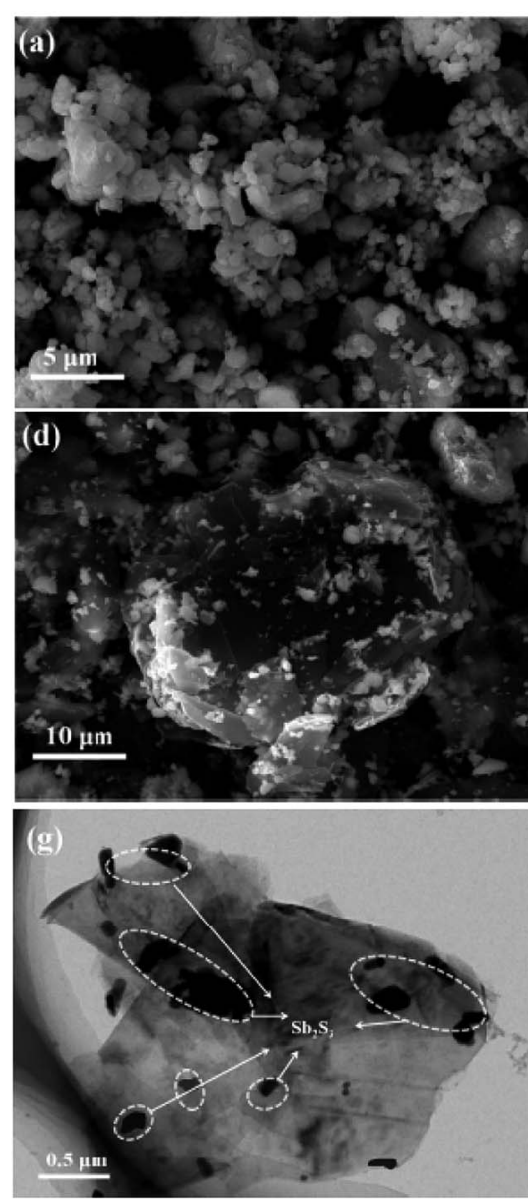
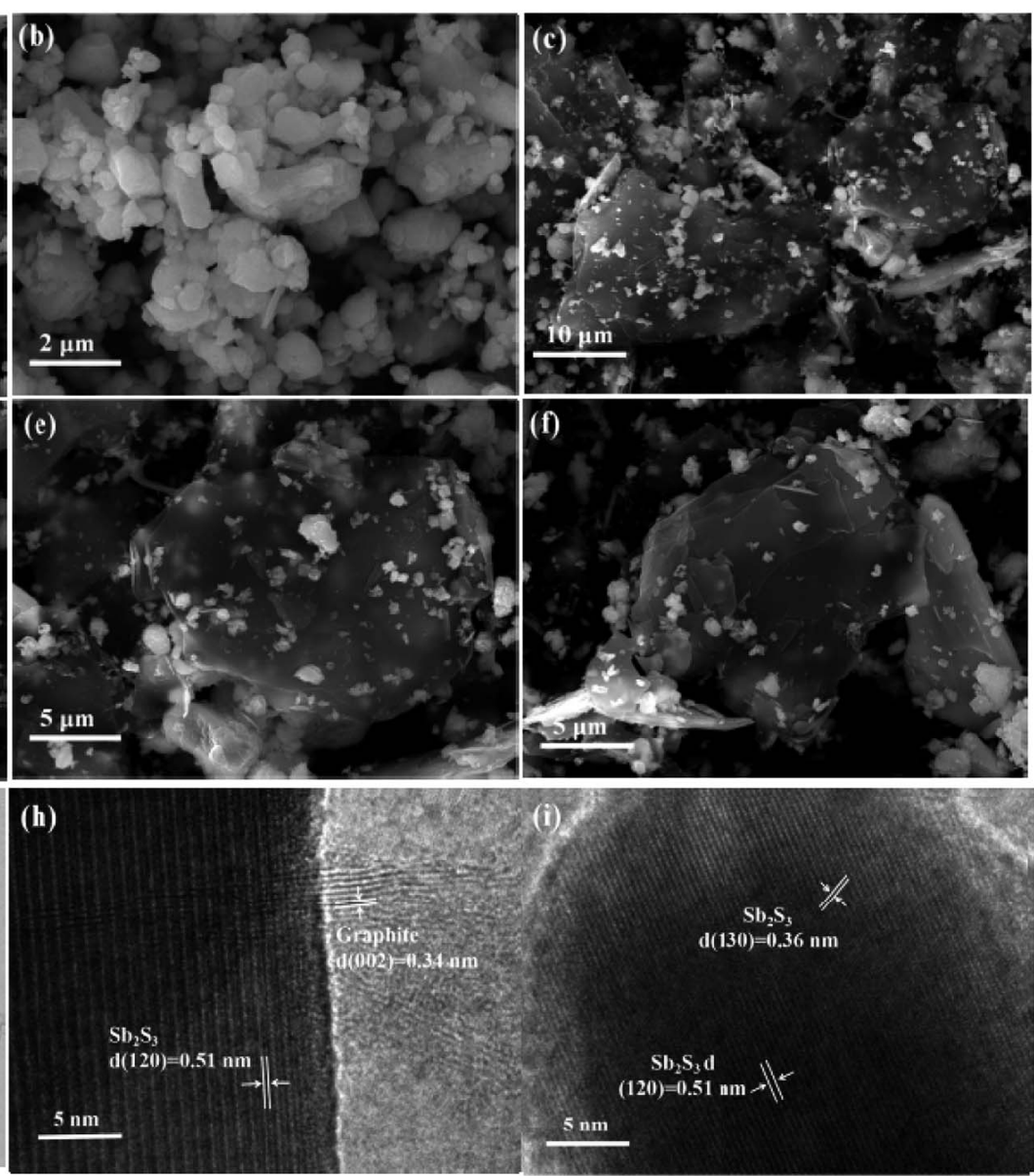

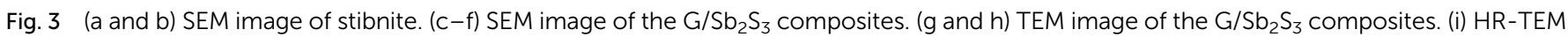
image of the $\mathrm{G} / \mathrm{Sb}_{2} \mathrm{~S}_{3}$ composites. 
Electrochemical properties of the $\mathrm{G} / \mathrm{Sb}_{2} \mathrm{~S}_{3}$ composites and stibnite mineral as SIBs anodes were evaluated by cyclic voltammetry in the potential range of 0.01-2.5 V. As shown in Fig. $4 \mathrm{a}$, two current peaks at $0.78 \mathrm{~V}$ and $0.12 \mathrm{~V}$ were revealed in the initial cathodic scan, which were ascribed to the conversion reaction with sulfur atoms in composites $\left(\mathrm{Sb}_{2} \mathrm{~S}_{3}+6 \mathrm{Na}^{+}+6 \mathrm{e}^{-} \rightarrow\right.$ $\left.2 \mathrm{Sb}+3 \mathrm{Na}_{2} \mathrm{Sb}\right)$, alloying reaction of antimony with sodium $(2 \mathrm{Sb}+$ $6 \mathrm{Na}^{+}+6 \mathrm{e}^{-} \rightarrow 2 \mathrm{Na}_{3} \mathrm{Sb}$ ) and the side reaction to form the solid electrolyte interface (SEI) on the surface of the electrode, respectively. ${ }^{36}$

In the succeeding cathodic scans, the differences of $\mathrm{CV}$ curves could be explained by the formation of an SEI and other irreversible reactions in the initial cycle. Furthermore, the area of the initial scan was larger than that of the subsequent cycles, suggesting that its initial capacity was higher than that in the subsequent cycles. ${ }^{37}$ During the anodic scan, the peaks at $0.81 \mathrm{~V}$ and $1.61 \mathrm{~V}$ were respectively ascribed to the dealloying reaction $\left(2 \mathrm{Na}_{3} \mathrm{Sb} \rightarrow 2 \mathrm{Sb}+6 \mathrm{Na}^{+}+6 \mathrm{e}^{-}\right)$and the formation of $\mathrm{Sb}_{2} \mathrm{~S}_{3}(2 \mathrm{Sb}+$ $\left.3 \mathrm{Na}_{2} \mathrm{~S} \rightarrow \mathrm{Sb}_{2} \mathrm{~S}_{3}+6 \mathrm{Na}^{+}+6 \mathrm{e}^{-}\right) .^{38}$

The galvanostatic cycling test was conducted to investigate the electrochemical behaviors of the $\mathrm{G} / \mathrm{Sb}_{2} \mathrm{~S}_{3}$ composites at the current density of $0.1 \mathrm{~A} \mathrm{~g}^{-1}$ in the potential range of $0.01-2.5 \mathrm{~V}$. As illustrated in Fig. 4c, in the first discharge profile, two smooth voltage plateaus at $1.18-0.85 \mathrm{~V}$ and $0.67-0.31 \mathrm{~V}$ corresponded to the reductive transformation and alloying reactions, respectively. In contrast, the voltage plateaus around at 0.63$1.16 \mathrm{~V}$ and $1.25-1.46 \mathrm{~V}$ were ascribed to the dealloying reactions and desodiation reactions in the charge profiles. Moreover, these plateau regions of discharge/charge agree well with the related $\mathrm{CV}$ curves.
The cycling performances of the $\mathrm{G} / \mathrm{Sb}_{2} \mathrm{~S}_{3}$ and stibnite mineral were studied at the current density of $0.1 \mathrm{~A} \mathrm{~g}^{-1}$ in the voltage range of $0.01-2.5 \mathrm{~V}$. The $\mathrm{G} / \mathrm{Sb}_{2} \mathrm{~S}_{3}$ composites and stibnite mineral revealed a completely different electrochemical performance because of the introduction of graphite. As illustrated in Fig. $4 d$, the $\mathrm{G} / \mathrm{Sb}_{2} \mathrm{~S}_{3}$ composite delivered the initial charge/discharge capacity of $542.8 / 864 \mathrm{~mA} \mathrm{~h} \mathrm{~g}{ }^{-1}$ with the coulombic efficiency (CE) of $62.76 \%$, whereas the stibnite mineral exhibited the initial charge/discharge capacity of 617.8/ $1008.3 \mathrm{~mA} \mathrm{~h} \mathrm{~g}^{-1}$ with the lower CE of $61.27 \%$. In addition, low initial coulombic efficiency is a common problem in conversion-alloying type materials. ${ }^{39}$ On the one hand, the formation of SEI originates from the decomposition of organic electrolytes at low voltages and the side reactions of the oxygencontaining functional groups on the surface of graphite with sodium ions, which can cause irreversible capacity. ${ }^{40}$ However, a stable SEI may also alleviate the irreversible reactions, which can improve coulombic efficiency in subsequent cycles evidently ${ }^{41}$ Encouragingly, the $\mathrm{G} / \mathrm{Sb}_{2} \mathrm{~S}_{3}$ composites still exhibit the reversible capacity of $407 \mathrm{~mA} \mathrm{~h} \mathrm{~g}{ }^{-1}$ with a $75.2 \%$ capacity retention, which are better than stibnite ore with $190.1 \mathrm{~mA} \mathrm{~h} \mathrm{~g}^{-1}$ and the capacity retention of $30.7 \%$ after 80 cycles. Evidently, the introduction of graphite could improve the capacity and reversibility of the stibnite mineral.

As shown in Fig. 5a, the rate performances of the $\mathrm{G} / \mathrm{Sb}_{2} \mathrm{~S}_{3}$ composites and stibnite mineral were further studied at different currents ranging from $0.1 \mathrm{~A} \mathrm{~g}^{-1}$ to $1 \mathrm{~A} \mathrm{~g}^{-1}$. The $\mathrm{G} / \mathrm{Sb}_{2} \mathrm{~S}_{3}$ composites delivered the average reversible capacities of 642.3 , 507.6, 392.1 and $264.9 \mathrm{~mA} \mathrm{~h} \mathrm{~g}^{-1}$ at the current densities of 0.1, $0.3,0.5$ and $1 \mathrm{Ag}^{-1}$, respectively. A similar capacity loss could be
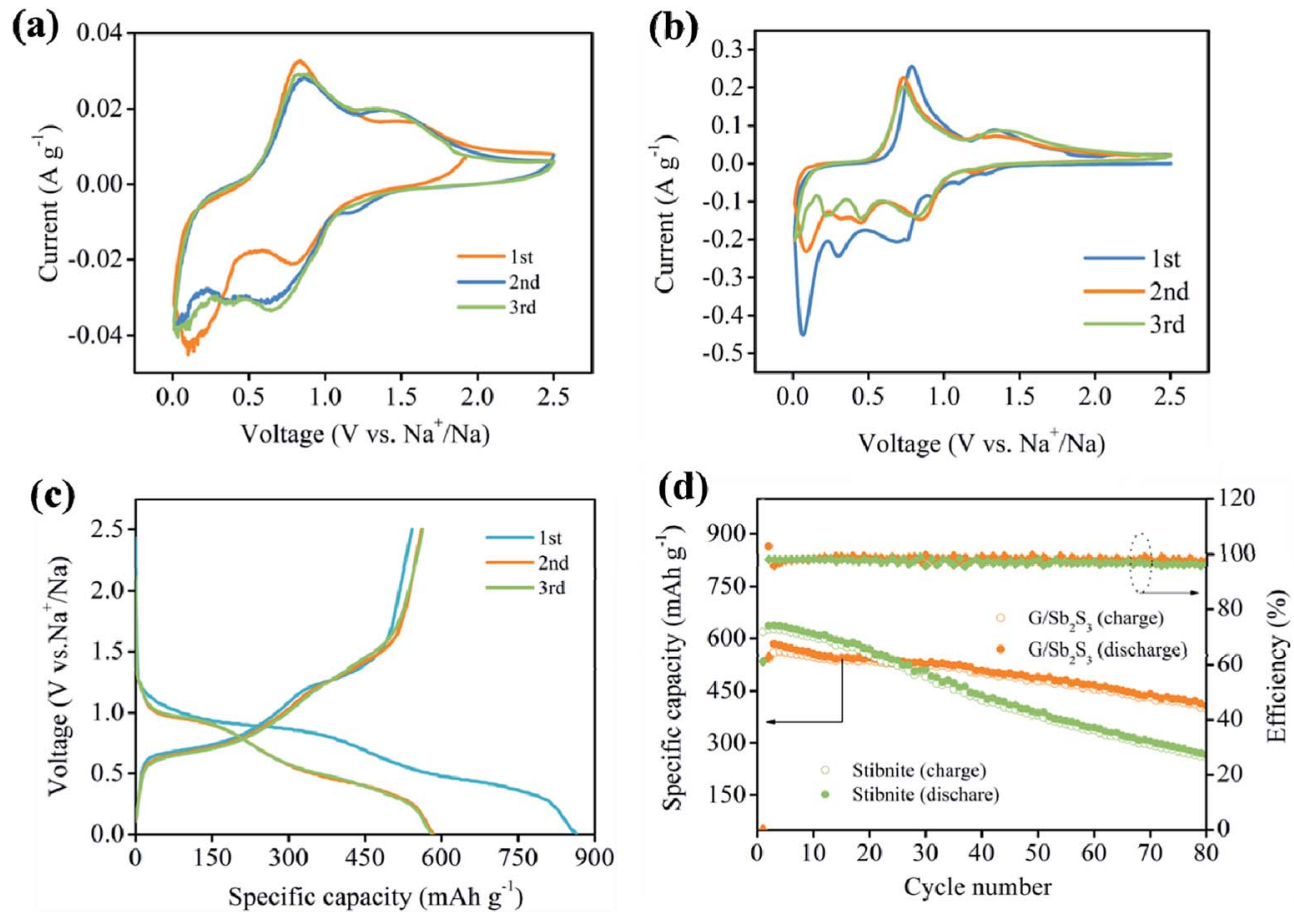

Fig. 4 Cyclic voltammograms of initial three cycles of (a) $\mathrm{G} / \mathrm{Sb}_{2} \mathrm{~S}_{3}$ composites, (b) stibnite. (c) Galvanostatic discharge/charge curves of $\mathrm{G} / \mathrm{Sb}_{2} \mathrm{~S}_{3}$ composites. (d) Cycling performance and coulombic efficiencies of $\mathrm{G} / \mathrm{Sb}_{2} \mathrm{~S}_{3}$ and stibnite. 


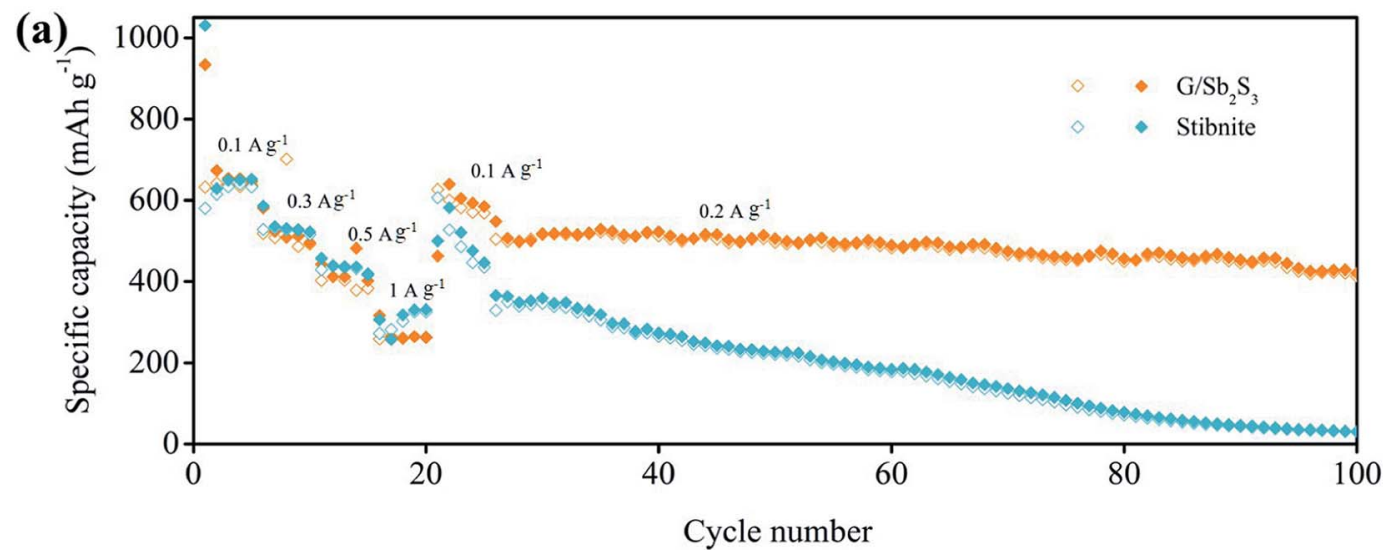

(b)

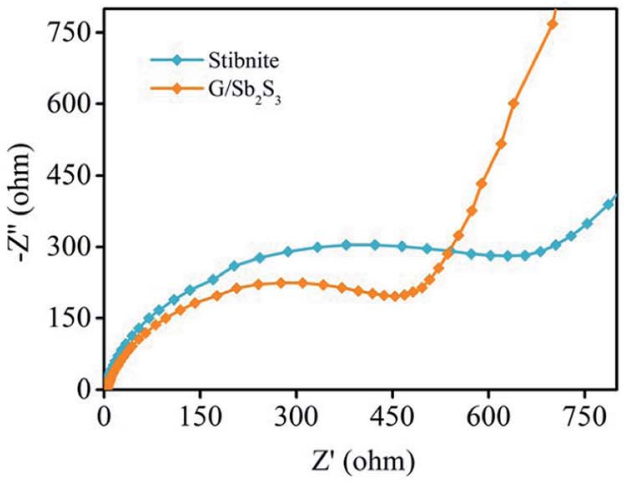

(c)

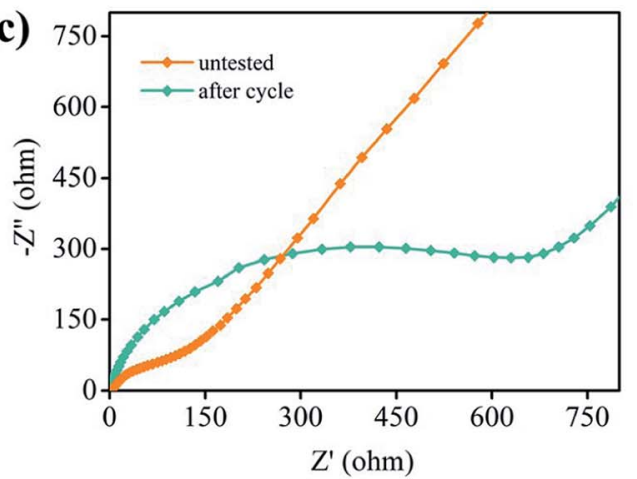

Fig. 5 (a) Rate performance of the $\mathrm{Sb}_{2} \mathrm{~S}_{3}$ electrode. (b) Nyquist plots of $\mathrm{G} / \mathrm{Sb}_{2} \mathrm{~S}_{3}$ and stibnite at the initial state. (c) Nyquist plots of $\mathrm{G} / \mathrm{Sb}_{2} \mathrm{~S}_{3}$ at different states.

observed in stibnite mineral. Furthermore, the average reversible capacity of the $\mathrm{G} / \mathrm{Sb}_{2} \mathrm{~S}_{3}$ composites could recover to $595 \mathrm{~mA} \mathrm{~h} \mathrm{~g}^{-1}$ when the current density was back to $0.1 \mathrm{~A} \mathrm{~g}^{-1}$ after 20 cycles. The cycling stability is key indicator to evaluate anode materials for application. Herein, the $\mathrm{G} / \mathrm{Sb}_{2} \mathrm{~S}_{3}$ composites were further studied at the current density of $0.2 \mathrm{~A} \mathrm{~g}^{-1}$ following the rate evaluation. After 75 cycles, the reversible capacity was $422 \mathrm{~mA} \mathrm{~h} \mathrm{~g}^{-1}$ with the capacity retention of $82.9 \%$. However, the stibnite mineral delivered poorer cycling performance. According to these differences, graphites in the composites might have a positive influence on enhancing the electrochemical performance of the stibnite mineral. Electrochemical impedance spectroscopy (EIS) was conducted in the frequency range from 0.01 to $100 \mathrm{kHz}$ at room temperature. The typical Nyquist plot consists of a depressed semicircle in the medium-high frequency region and a sloping line in the low frequency region, corresponding to the formation of a passivation layer and impedance between the electrolyte and active materials. ${ }^{42}$ Moreover, the charge transfer impedance $\left(R_{\mathrm{ct}}\right)$ as the main part of the whole kinetic impedance of the battery was illustrated by the semicircle at a medium frequency, which could be computed via utilizing the diameter of the semicircle. ${ }^{40}$ The Warburg impedance was evaluated to the diffusion process of sodium ions in anode materials, which is depicted in the sloping line at the low frequency. ${ }^{40}$ As illustrated in Fig. 5b, the $\mathrm{G} / \mathrm{Sb}_{2} \mathrm{~S}_{3}$ composites delivered lower computed $R_{\mathrm{ct}}(547 \Omega)$ than that of stibnite mineral electrode (785 $\Omega$ ), indicating the decreased charge transfer of $\mathrm{G} / \mathrm{Sb}_{2} \mathrm{~S}_{3}$ composites at the interface of electrode and electrolyte. Furthermore, the slope of $\mathrm{G} / \mathrm{Sb}_{2} \mathrm{~S}_{3}$ was more vertical than that of stibnite mineral at low frequency, suggesting better diffusion of sodium ions in the electrode. ${ }^{42}$ From the Fig. $5 \mathrm{c}$, the initial impedance of $\mathrm{G} / \mathrm{Sb}_{2} \mathrm{~S}_{3}$ composites were higher than the cycled electrode, suggesting an activation process and formation of stable SEI on the surface of the electrode during the insertion/desertion process. The improved diffusivity of sodium ions and conductivity of $\mathrm{G} / \mathrm{Sb}_{2} \mathrm{~S}_{3}$ composites benefited from the introduction of graphite, which was initiated to enhance the kinetics of the electrochemical reaction.

\section{Conclusion}

In summary, the $\mathrm{G} / \mathrm{Sb}_{2} \mathrm{~S}_{3}$ composites were successfully fabricated using the natural stibnite mineral and graphite via a novel and facile strategy, and their sodium storage performance was also investigated. Compared with the pure stibnite mineral, the $\mathrm{G} / \mathrm{Sb}_{2} \mathrm{~S}_{3}$ composite electrode exhibited excellent cycling rate properties as the SIB anodes. The improved performance was most possibly ascribed to the introduction of graphite that might have effectively enhanced the conductivity of the stibnite mineral and accommodated the volume changes of $\mathrm{Sb}_{2} \mathrm{~S}_{3}$. This study demonstrates that natural stibnite minerals as first-hand 
materials can be applied in SIBs and is expected to provide environmental ideas that natural minerals after simple modifications can be directly applied in the energy storage domain.

\section{Conflicts of interest}

There are no conflicts to declare.

\section{Acknowledgements}

This work was financially supported by the Young Elite Scientists Sponsorship Program by CAST (2017QNRC001), National Natural Science Foundation of China (51904342, 51622406, 21673298), Hunan Provincial Natural Science Foundation of China (2018JJ3633), National Postdoctoral Program for Innovative Talents (BX00192), and National Key Research and Development Program of China (2017YFB0102000, 2018YFB0104200).

\section{References}

1 S. Dong, C. Li, X. Ge, Z. Li, X. Miao and L. Yin, ZnS-Sb $\mathrm{S}_{3} @ \mathrm{C}$ Core-Double Shell Polyhedron Structure Derived from MetalOrganic Framework as Anodes for High Performance Sodium Ion Batteries, ACS Nano, 2017, 11, 6474-6482.

2 E. M. Lotfabad, J. Ding, K. Cui, A. Kohandehghan, W. P. Kalisvaart, M. Hazelton and D. Mitlin, High-Density Sodium and Lithium Ion Battery Anodes from Banana Peels, ACS Nano, 2014, 8, 7115-7129.

3 J. Song, P. Yan, L. Luo, X. Qi, X. Rong, J. Zheng, B. Xiao, S. Feng, C. Wang, Y.-S. Hu, Y. Lin, V. L. Sprenkle and X. Li, Yolk-shell structured Sb@C anodes for high energy Na-ion batteries, Nano Energy, 2017, 40, 504-511.

$4 \mathrm{~W}$. Yang, H. Wang, T. Liu and L. Gao, A Bi ${ }_{2} \mathrm{~S}_{3} @ \mathrm{CNT}$ nanocomposite as anode material for sodium ion batteries, Mater. Lett., 2016, 167, 102-105.

5 H. Hou, G. Zou, P. Ge, G. Zhao, W. Wei, X. Ji and L. Huang, Synergistic effect of cross-linked carbon nanosheet frameworks and $\mathrm{Sb}$ on the enhancement of sodium storage performances, New J. Chem., 2017, 41, 13724-13731.

6 C. Zhang, X. Wang, Q. Liang, X. Liu, Q. Weng, J. Liu, Y. Yang, Z. Dai and K. Ding, Amorphous Phosphorus/Nitrogen-Doped Graphene Paper for Ultrastable Sodium-Ion Batteries, Nano Lett., 2016, 16, 2054-2060.

7 Z. Liu, X.-Y. Yu, X. W. Lou and U. Paik, Sb@C coaxial nanotubes as a superior long-life and high-rate anode for sodium ion batteries, Energy Environ. Sci., 2016, 9, 23142318.

8 G. Zhao, G. Zou, X. Qiu, S. Li, T. Guo, H. Hou and X. Ji, Roselike N-doped Porous Carbon for Advanced Sodium Storage, Electrochim. Acta, 2017, 240, 24-30.

$9 \mathrm{Y}$. Zhao and A. Manthiram, Amorphous $\mathrm{Sb}_{2} \mathrm{~S}_{3}$ embedded in graphite: a high-rate, long-life anode material for sodiumion batteries, Chem. Commun., 2015, 51, 13205-13208.

10 T. Zheng, G. Li, L. Zhao and Y. Shen, Flowerlike $\mathrm{Sb}_{2} \mathrm{~S}_{3} / \mathrm{PPy}$ Microspheres Used as Anode Material for High-
Performance Sodium-Ion Batteries, Eur. J. Inorg. Chem., 2018, 2018, 1224-1228.

11 M. Kriisa, M. Krunks, I. Oja Acik, E. Kärber and V. Mikli, The effect of tartaric acid in the deposition of $\mathrm{Sb}_{2} \mathrm{~S}_{3}$ films by chemical spray pyrolysis, Mater. Sci. Semicond. Process., 2015, 40, 867-872.

12 Z. Yi, Q. Han, Y. Cheng, Y. Wu and L. Wang, Facile synthesis of symmetric bundle-like $\mathrm{Sb}_{2} \mathrm{~S}_{3}$ micron-structures and their application in lithium-ion battery anodes, Chem. Commun., 2016, 52, 7691-7694.

13 Y. Zhu, P. Nie, L. Shen, S. Dong, Q. Sheng, H. Li, H. Luo and $\mathrm{X}$. Zhang, High rate capability and superior cycle stability of a flower-like $\mathrm{Sb}_{2} \mathrm{~S}_{3}$ anode for high-capacity sodium ion batteries, Nanoscale, 2015, 7, 3309-3315.

14 J. Zhou, B. Yan, J. Yang, Y. Yang, W. Zhou, H. Lan, H. Wang and L. Guo, A densely packed $\mathrm{Sb}_{2} \mathrm{O}_{3}$ nanosheet-graphene aerogel toward advanced sodium-ion batteries, Nanoscale, 2018, 10, 9108-9114.

15 S. Liu, Z. Cai, J. Zhou, M. Zhu, A. Pan and S. Liang, Highperformance sodium-ion batteries and flexible sodium-ion capacitors based on $\mathrm{Sb}_{2} \mathrm{X}_{3}(\mathrm{X}=\mathrm{O}, \mathrm{S})$ /carbon fiber cloth, $J$. Mater. Chem. A, 2017, 5, 9169-9176.

16 C. Yan, G. Chen, R. Jin, X. Zou, H. Xu and C. Lv, Well-defined $\mathrm{Sb}_{2} \mathrm{~S}_{3}$ nanostructures: citric acid-assisted synthesis, electrochemical hydrogen storage properties, Cryst. Res. Technol., 2013, 48, 566-573.

17 N. Maiti, S. H. Im, Y. H. Lee and S. I. Seok, Urchinlike nanostructure of single-crystalline nanorods of $\mathrm{Sb}_{2} \mathrm{~S}_{3}$ formed at mild reaction condition, ACS Appl. Mater. Interfaces, 2012, 4, 4787-4791.

18 K. Zhou, M. Hu, Y.-b. He, L. Yang, C. Han, R. Lv, F. Kang and B. Li, Transition metal assisted synthesis of tunable pore structure carbon with high performance as sodium/lithium ion battery anode, Carbon, 2018, 129, 667-673.

19 C. G. Anderson, The metallurgy of antimony, Chem. Erde, 2012, 72, 3-8.

20 S. Li, H. Tang, P. Ge, F. Jiang, J. Zhou, C. Zhang, H. Hou, W. Sun and X. Ji, Electrochemical Investigation of Natural Ore Molybdenite $\left(\mathrm{MoS}_{2}\right)$ as a First-Hand Anode for Lithium Storages, ACS Appl. Mater. Interfaces, 2018, 10, 6378-6389.

21 H. Liu, J. Huang, X. Li, J. Liu and Y. Zhang, $\mathrm{SnO}_{2}$ nanorods grown on graphite as a high-capacity anode material for lithium ion batteries, Ceram. Int., 2012, 38, 5145-5149.

22 J. Kong, H. Wei, D. Xia and P. Yu, High-performance $\mathrm{Sb}_{2} \mathrm{~S}_{3} /$ $\mathrm{Sb}$ anode materials for Li-ion batteries, Mater. Lett., 2016, 179, 114-117.

23 A. S. Hameed, M. V. Reddy, J. L. T. Chen, B. V. R. Chowdari and J. J. Vittal, RGO/Stibnite Nanocomposite as a Dual Anode for Lithium and Sodium Ion Batteries, ACS Sustainable Chem. Eng., 2016, 4, 2479-2486.

24 G. Zou, C. Wang, H. Hou, C. Wang, X. Qiu and X. Ji, Controllable Interlayer Spacing of Sulfur-Doped Graphitic Carbon Nanosheets for Fast Sodium-Ion Batteries, Small, 2017, 13, 1700762.

25 G. Wang, X. Xiong, Z. Lin, C. Yang, Z. Lin and M. Liu, Sb/C composite as a high-performance anode for sodium ion batteries, Electrochim. Acta, 2017, 242, 159-164. 
26 J. Ibáñez, J. A. Sans, C. Popescu, J. López-Vidrier, J. J. ElviraBetanzos, V. P. Cuenca-Gotor, O. Gomis, F. J. Manjón, P. Rodríguez-Hernández and A. Muñoz, Structural, Vibrational, and Electronic Study of $\mathrm{Sb} 2 \mathrm{~S} 3$ at High Pressure, J. Phys. Chem. C, 2016, 120, 10547-10558.

27 Q. Ru, X. Chen, B. Wang, Q. Guo, Z. Wang, X. Hou and S. Hu, Biological carbon skeleton of lotus-pollen surrounded by rod-like $\mathrm{Sb}_{2} \mathrm{~S}_{3}$ as anode material in lithium ion battery, Mater. Lett., 2017, 198, 57-60.

28 V. P. Zakaznova-Herzog, S. L. Harmer, H. W. Nesbitt, G. M. Bancroft, R. Flemming and A. R. Pratt, High resolution XPS study of the large-band-gap semiconductor stibnite $\left(\mathrm{Sb}_{2} \mathrm{~S}_{3}\right)$ : structural contributions and surface reconstruction, Surf. Sci., 2006, 600, 348-356.

29 S. Wang, S. Liu, X. Li, C. Li, R. Zang, Z. Man, Y. Wu, P. Li and G. Wang, $\mathrm{SnS}_{2}-\mathrm{Sb}_{2} \mathrm{~S}_{3}$ Heterostructures Anchored on Reduced Graphene Oxide Nanosheets with Superior Rate Capability for Sodium-Ion Batteries, Chem. Eur J., 2018, 24, 3873-3881.

30 Y. Wu, L.-Y. Wang, Y.-F. Li, Z.-Y. Zhao, L.-W. Yin, H. Li and Y.-J. Bai, KCl-Modified Graphite as High Performance Anode Material for Lithium-Ion Batteries with Excellent Rate Performance, J. Phys. Chem. C, 2017, 121, 13052-13058.

31 L. Chen, R. Lin and C. Yan, Nitrogen-doped double-layer graphite supported $\mathrm{CuCo}_{2} \mathrm{~S}_{4}$ electrode for highperformance asymmetric supercapacitors, Mater. Lett., 2019, 235, 6-10.

32 K. Xiao, Q. Z. Xu, K. H. Ye, Z. Q. Liu, L. M. Fu, N. Li, Y. B. Chen and Y. Z. Su, Facile Hydrothermal Synthesis of $\mathrm{Sb}_{2} \mathrm{~S}_{3}$ Nanorods and Their Magnetic and Electrochemical Properties, ECS Solid State Lett., 2013, 2, P51-P54.

33 J.-H. Choi, C.-W. Ha, H.-Y. Choi, H.-C. Shin, C.-M. Park, Y.-N. Jo and S.-M. Lee, $\mathrm{Sb}_{2} \mathrm{~S}_{3}$ embedded in amorphous $\mathrm{P} / \mathrm{C}$ composite matrix as high-performance anode material for sodium ion batteries, Electrochim. Acta, 2016, 210, 588-595.

34 X. Guo, X. Xie, S. Choi, Y. Zhao, H. Liu, C. Wang, S. Chang and $\mathrm{G}$. Wang, $\mathrm{Sb}_{2} \mathrm{O}_{3} / \mathrm{MXene}\left(\mathrm{Ti}_{3} \mathrm{C}_{2} \mathrm{~T}_{\mathrm{x}}\right)$ hybrid anode materials with enhanced performance for sodium-ion batteries, J. Mater. Chem. A, 2017, 5, 12445-12452.

35 L. Wang, J. Yang, J. Li, T. Chen, S. Chen, Z. Wu, J. Qiu, B. Wang, P. Gao, X. Niu and H. Li, Graphite as a potassium ion battery anode in carbonate-based electrolyte and ether-based electrolyte, J. Power Sources, 2019, 409, 24-30.

36 P. Ge, H. Hou, X. Ji, Z. Huang, S. Li and L. Huang, Enhanced stability of sodium storage exhibited by carbon coated $\mathrm{Sb}_{2} \mathrm{~S}_{3}$ hollow spheres, Mater. Chem. Phys., 2018, 203, 185-192.

37 J. Pan, Z. Zuo, J. Deng, Q. Yao, Z. Wang and H. Zhou, $\mathrm{Sb}_{2} \mathrm{~S}_{3}$ single crystal nanowires with comparable electrochemical properties as an anode for sodium ion batteries, Surf. Interfaces, 2018, 10, 170-175.

38 H. Hou, M. Jing, Z. Huang, Y. Yang, Y. Zhang, J. Chen, Z. Wu and $\mathrm{X}$. Ji, One-Dimensional Rod-Like $\mathrm{Sb}_{2} \mathrm{~S}_{3}$-Based Anode for High-Performance Sodium-Ion Batteries, ACS Appl. Mater. Interfaces, 2015, 7, 19362-19369.

39 S. Wang, S. Yuan, Y.-B. Yin, Y.-H. Zhu, X.-B. Zhang and J.-M. Yan, Green and Facile Fabrication of MWNTs@Sb $\mathrm{S}_{3} @ P P y$ Coaxial Nanocables for HighPerformance Na-Ion Batteries, Part. Part. Syst. Charact., 2016, 33, 493-499.

40 Y. Dong, S. Yang, Z. Zhang, J. M. Lee and J. A. Zapien, Enhanced electrochemical performance of lithium ion batteries using $\mathrm{Sb}_{2} \mathrm{~S}_{3}$ nanorods wrapped in graphene nanosheets as anode materials, Nanoscale, 2018, 10, 31593165.

41 M. Hu, Y. Jiang, W. Sun, H. Wang, C. Jin and M. Yan, Reversible conversion-alloying of $\mathrm{Sb}_{2} \mathrm{O}_{3}$ as a high-capacity, high-rate, and durable anode for sodium ion batteries, ACS Appl. Mater. Interfaces, 2014, 6, 19449-19455.

42 Z. Zhang, J. Zhao, M. Xu, H. Wang, Y. Gong and J. Xu, Facile synthesis of $\mathrm{Sb}_{2} \mathrm{~S}_{3} / \mathrm{MoS}_{2}$ heterostructure as anode material for sodium-ion batteries, Nanotechnology, 2018, 29, 335401. 